\title{
World Hypertension League: Its Scope, Purpose, and Impact in South Asia
}

\author{
${ }^{1}$ Daniel T Lackland, ${ }^{2} \mathrm{C}$ Venkata S Ram
}

How to cite this article: Lackland DT, Ram CVS. World Hypertension League: Its Scope, Purpose, and Impact in South Asia. Hypertens J 2016;2(2):55-56.

\section{Source of support: Nil}

Conflict of interest: None

\section{INTRODUCTION}

High blood pressure and hypertension have long been recognized as major global risk factors for cardiovascular disease, stroke, heart failure, end-stage renal disease, peripheral vascular disease, and cerebrovascular disease, with significant impact on more than a billion people worldwide. ${ }^{1}$ With consideration of the population health indicator of disability-adjusted life years (DALYs), high blood pressure is now considered as the number one risk factor in the world, including countries, such as India and the South Pacific region. ${ }^{2,3}$

Hypertension-related conditions, such as stroke, end-stage renal disease, and heart failure could have been prevented or delayed with treated and controlled high blood pressure, regardless of demographics. ${ }^{4}$ Thus, hypertension should be considered the most important preventable cause of premature death worldwide.

Structured prevention and management programs were based on the population premise, i.e., if the elevation of blood pressure with age can be prevented or reduced, hypertension-related outcomes, such as stroke, heart failure, and end-stage renal diseases can be significantly reduced. In addition to clinical treatment and control of elevated blood pressure, these programs incorporate risk factor reduction including

\footnotetext{
${ }^{1}$ President, ${ }^{2}$ Director

${ }^{1}$ Department of Neurology, World Hypertension League, Medical University of South Carolina, Charleston, South Carolina, USA

${ }^{2}$ World Hypertension League, South Asia Region, Apollo Institute for Blood Pressure Management, Apollo Blood Pressure Clinics Apollo Hospitals, Hyderabad, Telangana, India

Texas Blood Pressure Institute, Dallas Nephrology Associates University of Texas Southwestern Medical School, Dallas Texas, USA

Corresponding Author: Daniel T Lackland, President Department of Neurology, World Hypertension League, Medical University of South Carolina, Charleston, South California, USA Phone: +8438761141, e-mail: lackland@musc.edu
}

excess body weight; excess dietary sodium intake; reduced physical activity; inadequate intake of fruits, vegetables, and potassium; and excess alcohol intake. ${ }^{5}$ Over 20 years earlier, it was estimated that a $5 \mathrm{~mm} \mathrm{Hg}$ reduction of systolic blood pressure would result in a $14 \%$ overall reduction in mortality due to stroke. ${ }^{6}$ This was confirmed by a report demonstrating a significant reduction in the population distributions of systolic blood pressure consistent with the significant reduction in stroke mortality. ${ }^{4}$ These blood pressure and associated risk factors' reductions have been attributed to the public health and clinical successes. ${ }^{4}$

Cardiovascular diseases are responsible for significant morbidity and mortality in South Asia (Tables 1 and 2).

The World Hypertension League (WHL), which is in official relations with the World Health Organization (WHO), was established to focus on the global risks of hypertension and strategies and programs for population with high blood pressure control and prevention. The WHL is the only nongovernmental organization (NGO) at WHO with a mission strictly devoted to hypertension prevention, management, and control in the population. The inclusion of WHL and the South Pacific Regional Office among the professional NGOs at WHO is particularly helpful in stabilizing and facilitating ongoing projects, which include hypertension detection and surveillance, the production of hypertension awareness material for the public during World Hypertension Day, the development of combined sessions and symposia at international conferences, and involvement of WHO campaigns on salt reduction in global diets to prevent hypertension. ${ }^{7-12}$

The World Health Assembly, a WHO body, called for a globalaction to prevent noncommunicable diseases (NCDs)

Table 1: Health factors - South Asia

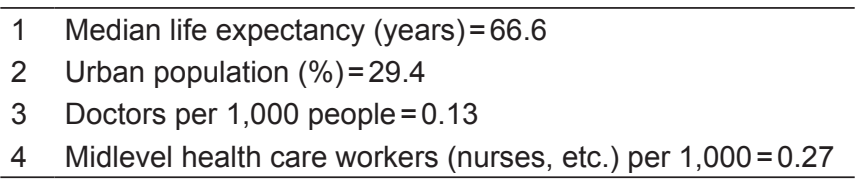
Adapted from Global Heart 2014;9:65-70

Table 2: Number of DALYs - South Asia

\begin{tabular}{lll}
\hline 1 & Ischemic heart disease & $31,010,200(51.2 \%)$ \\
2 & Stroke & $15,409,100(25.4 \%)$ \\
3 & Hypertensive heart disease & $3,588,080(5.99 \%)$ \\
\hline
\end{tabular}


and to reduce premature mortality (from NCDs) by $25 \%$ by 2015 . The action plan calls for close monitoring, detection, and aggressive control of risk factors for cardiovascular disease. However, this ambitious goal is not possible without a "national" policy for countries like India. The entire South Asia is under the grip of escalating CVD. It is extremely critical for governmental organizations and NGOs to work together to achieve the 2025 CVD reduction targets. The WHL is committed to assist and guide the South Asia region to combat the CVD burden by promoting lifestyle changes and methodologies to control hypertension.

Hypertension is the leading cause for NCDs in India and nearly $10 \%$ of all deaths in the country are attributable to hypertension. ${ }^{13}$ In less than a decade, the number of people with hypertension will increase to 214 million. ${ }^{14}$ Against this background, there is a huge gap between what is known about high blood pressure in India and what is being done to control it. The WHL calls for immediate action-based objectives for blood pressure control in India by increasing the awareness of this "silent" killer and by advocating massive screening, early diagnosis, and widespread therapeutic implications across India. This intent of WHL can be realized only through the efforts of Indian Society of Hypertension and other like-minded professional organizations.

A major objective of the WHL is professional education for the health care workforce team, including physicians, nurses, pharmacists, physician assistants, and community health care workers with access to the current evidence and resources for population hypertension detection, prevention, and control. The efforts of the WHL and the South Asia Regional Office have shown significant impact with great expectations for future risk reductions from elevated blood pressure throughout the world.

\section{REFERENCES}

1. Kearney PM, Whelton M, Reynolds K, Muntner P, Whelton PK, He J. Global burden of hypertension: analysis of worldwide data. Lancet 2005 Jan 15-21;365(9455):217-223.

2. Danaei G, Finucane MM, Lin JK, Singh GM, Paciorek CJ, Cowan MJ, Farzadfar F, Stevens GA, Lim SS, Riley LM, et al. National, regional, and global trends in systolic blood pressure since 1980: systematic analysis of health examination surveys and epidemiological studies with 786 country-years and 5.4 million participants. Lancet 2011 Feb 12;377(9765):568-577.

3. Murray CJ, Vos T, Lozano R, Naghavi M, Flaxman AD, Michaud C, Ezzati M, Shibuya K, Salomon JA, Abdalla S, et al. Disability-adjusted life years (DALYs) for 291 diseases and injuries in 21 regions, 1990-2010: a systematic analysis for the Global Burden of Disease Study 2010 [published correction appears in Lancet 2013;381:628]. Lancet 2012 Dec;380(9559):2197-2223.

4. Lackland DT, Roccella EJ, Deutsch AF, Fornage M, George MG, Howard G, Kissela BM, Kittner SJ, Lichtman JH, Lisabeth LD, et al. Factors influencing the decline in stroke mortality: a statement from the American Heart Association/American Stroke Association. Stroke 2014 Jan;45(1):315-353.

5. Whelton PK, He J, Appel LJ, Cutler JA, Havas S, Kotchen TA, Roccella EJ, Stout R, Vallbona C, Winston MC, et al. Primary prevention of hypertension: clinical and public health advisory from the national high blood pressure education program. JAMA 2002 Oct 16;288(15):1882-1888.

6. Stamler R. Implications of the intersalt study. Hypertension 1991 Jan;17(Suppl 1):16-20.

7. Campbell NR, Lackland DT, Lisheng L, Zhang XH, Nilsson PM, Niebylski ML. The World Hypertension League Executive. The World Hypertension League: where now and where to in salt reduction. Cardiovasc Diagn Ther 2015 Jun;5(3): 238-242.

8. Campbell NRC, Lackland DT, Lisheng L, Zhang XH, Nilsson PM, Redburn KA, Niebylski ML. The World Hypertension League challenges hypertension and cardiovascular organizations to develop strategic plans for the prevention and control of hypertension. J Clin Hypertens 2015 May;17(5):325-327.

9. Campbell NRC, Lackland DT, Niebylski ML. 2014 dietary salt fact sheet of the World Hypertension League, International Society of Hypertension, Pan American Health Organization Technical Advisory Group on Cardiovascular Disease Prevention Through Dietary Salt Reduction, the World Health Organization Collaborating Centre on Population Salt Reduction, and World Action on Salt \& Health. J Clin Hypertens 2015 Jan;17(1):7-9.

10. Campbell NR, Berbari AE, Cloutier L, Gelfer M, Kenerson JG, Khalsa TK, Lackland DT, Lemogoum D, Mangat BK, Mohan S, et al. Policy statement of the world hypertension league on noninvasive blood pressure measurement devices and blood pressure measurement in the clinical or community setting. J Clin Hypertens 2014 May;16(5):320-322.

11. KhalsaTK,CampbellNR,LacklandDT,LishengL,NiebylskiML, Zhang XH. Needs assessment of national hypertension organizations for hypertension prevention and control programs. J Clin Hypertens 2014 Dec;16(12):848-855.

12. Campbell N, Lackland D, Chockalingam A, Lisheng L, Schiffrin EL, Harrap S, Touyz RM, Burrell L, Ramírez A, Schmieder R, et al. The World Hypertension League and International Society of Hypertension call on governments, nongovernmental organizations, and the food industry to work to reduce dietary sodium. J Clin Hypertens 2014 Feb;16(2):99-100.

13. Patel V, Chatterji S, Chisholm D, Ebrahim S, Gopalakrishna G, Mathers C, Mohan V, Prabhakaran D, Ravindran RD, Reddy KS. Chronic diseases and injuries in India. Lancet 2011;377(9763):413-428.

14. Reddy KS, Shah B, Varghese C, Ramadoss A. Responding to the threat of chronic diseases in India. Lancet $2005 \mathrm{Nov}$ 12;366(9498):1744-1749. 